\title{
SMALL \& MEDIUM ENTERPRISE ASSESSMENT IN CZECH REPUBLIC \& RUSSIA USING MARKETING ANALYTICS METHODOLOGY
}

\author{
Dasan, P.
}

This paper aims to focus on the determinants influencing the internationalization of small and medium-sized enterprises (SMEs) in Czech Republic and Russia. The objective is to investigate and evaluate the business environment and, then, examine the importance of developing and promoting entrepreneurship to allow SMEs in Czech \& Russia to develop a competitive position in the international marketplace. An overview of the current economic situation facing SMEs in $\mathrm{CZ} \& \mathrm{RU}$ is provided. Then the factors necessary for the expansion of the business will be discussed, along with the challenges of overcoming the resource gaps to be identified. We have conducted empirical surveys along with the use of SPSS statistical tools to predict the potential of revenue growth in SME sector. Information is provided concerning the current situation for SMEs in CZ \& RU and the challenges encountered as they face a business environment that is becoming more competitive. We also found that SMEs are increasingly more integrated into the global economy and not limited to regional/international activities. Quantitative analysis shows that there is significant potential for SMEs for the next couple of years despite the economic uncertainty. This paper integrates entrepreneurship, and the resource-based internationalization of SMEs in Czech Republic \& Russia, specifically focusing on the use of technology.

JEL Classification: C40, C49, C63, C81, C83

Keywords: Entrepreneurs, International trade, Small to medium-sized enterprises, Europe, Marketing Analytics

\section{Introduction}

In an exacting economic environment, small and medium-sized enterprises (SMEs) have been presented with a challenge: to progressively increase the profitability of their businesses against the backdrop of commonly weak demand. This report summarizes the results of research into the performance and competitiveness of SMEs in this business environment, with a specific focus on attempts by SMEs to 'internationalize' their businesses and how this impacts their growth.

\section{The definition of SMEs}

Small and medium-sized enterprises (SMEs) are a very heterogeneous group. SMEs are found in a wide array of business activities, ranging from the single artisan producing agricultural implements for the village market, the coffee shop on the corner, the Internet cafe in a small town to a small sophisticated engineering or software firm selling to overseas markets, and a medium-sized automotive parts manufacturer selling to multinational automakers in the domestic and foreign markets. The owners may or may not be poor, while the firms operate in very different markets (urban, rural, local, national, regional and international) which embody different levels of skills, capital, sophistication and growth orientation, and may be in the formal or the informal economy.

The statistical definition of SMEs varies by country but is usually based on the number of employees, value of sales and/or value of assets. Due to its ease of collection, the most commonly used variable is the number of employees. The EU, a large number of OECD members, as well as transition and developing countries set the upper limit of the number of employees in the SMEs between 200-250; there are also a few exceptions such as Japan (300 employees) and the USA (500 employees). At the lower end of the SME sector, a large number of countries define a group, making up a mixture of the self-employed and "micro" enterprises, with less than 10 
employees. Irrespective of the level of development of an economy, a significant proportion of micro and, sometimes, small enterprises are found in the informal sector, or the shadow economy. Schneider (2003) compared the size of the informal sector in 22 transition (former Soviet Union and Central and Eastern Europe) and 21 OECD economies from 2000-2002 and found that the size of the informal sector amounted to an average of $16.7 \%, 29.2 \%$ and $44.8 \%$ of GDP in OECD, Central and Eastern Europe and the former Soviet Union economies, respectively.

\section{The importance of SMEs in a global economy}

Global economic integration is changing the competitive paradigm in which all businesses operate, requiring an international expansion strategy to positively impact long-term growth and survival (Karagozoglou and Lindell, 1998). The small business sector has become more important as they emerge as a dominant force impacting the growth of national economies (Shridhar, 2006). However, there are a number of disadvantages inherently faced by SMEs as they transition into international environments (Chen and Huang, 2004). Managers of non-exporting SMEs perceive the international environment as being risky, unprofitable and unmanageable, primarily due to misinformation and lack of experience with global business (Malekzadeh and Nahavandi, 1985). SMEs, due to their size limitations, often have limited financial capital and lack the necessary human resources. Many operators of small businesses lack experience in developing an international strategy (Tesar and Moini, 1998). There are also disadvantages related to a lack of competitive power as a consequence of the size of the organization. SMEs have difficulty in influencing global pricing as they rely on only a small customer base, and are limited in expansion due to minimal access to financial resources (Kalantaridis, 2004). Faced with the need to overcome significant weaknesses, the strategic importance of SMEs has been identified in several factors. They are responsible for growing employment at a faster rate than organizations; they increase the competitive intensity of the market and reduce the monopolistic positions of large organizations; they encourage the development of entrepreneurial skills and innovation. Larger SMEs in the USA account for three out of every four new jobs and contribute to providing over half of the gross domestic product (Underwood, 2004). From 1992 to 1999, the number of SMEs that were involved in exporting increased over 100 percent, to nearly 97 percent of all exporting firms in the USA, and accounting for $\$ 168.5$ billion in value (Underwood, 2004).
SMEs typically provide capabilities that their larger customers do not have or cannot cost-effectively create, such as:

- Agility in responding to changes in technologies, markets, and trends,

- Efficiency due, in part, to less bureaucracy,

- Initiative and entrepreneurial behavior on the part of employees resulting in higher levels of creativity and energy and a greater desire for success,

- Access to specialized proprietary technologies, process capabilities, and expertise,

- Shorter time-to-market because operations are small and focused,

- Lower labor costs and less restrictive labor contracts,

- Spreading the costs of specialized capabilities over larger production volumes by serving multiple customers,

- Lower cost, customer focused, and customized services, including documentation, after-sales support, spare parts, recycling, and disposal.

\section{SMEs' international competitiveness}

As trade barriers are removed, logistics and communication costs fall, small and medium-sized enterprises have adapted to new challenges to stay competitive in the international marketplace. These developments have also opened up opportunities for SMEs. Their integration into the global economy has prompted them to develop new international activities such as attempting to open new markets, thus adding more value to their products and services while reducing their cost base.

Assessing a SME's international competitiveness requires consideration of the economic, political and social aspects within the SME's country of origin, as much as looking at the SME itself. Both levels of analysis have to be taken into account in this research:

The macro level, 'national' competitive advantages, such as access to new technologies, skilled labor, market structure, logistics and infrastructure; and

The micro level, company-specific competitive advantages, such as price, quality, service, responsiveness and innovation.

\section{Business Environment in Russia (SME Perceptive)}

General uncertainty regarding almost every aspect of business is commonly considered the most prominent characteristic of the Russian business environment. However, this is not the only factor that makes life difficult for business operators in Russia. Transaction and 
start-up costs are large because of the inadequacies of the Russian legal framework and frequent changes in regulations. Securing financial resources, particularly at the early stage of the project, is a daunting task. Direct assistance programs and venture capitalists are all but non-existent, while a combination of state regulations and banking policies have placed credit out of reach for small and medium-size enterprises.

Of 120 trillion rubles ( $\$ 21$ billion) in banking credits issued in 1996, only 1.2 percent was medium- and longterm credits to businesses (Berezanskaya, 1997). Russia is characterized by mistrust between participants in business transactions. Consequently, the need for building strategic alliances has grown in importance, as even the most explicit contractual agreements are not enough to guarantee access to resources. In Russia, the tradition of relying on informal arrangements and networks as an element of business has a long history (Kuznetsov et al., 2000), and in this period of transition, successful networking has become an even more significant factor for success.

The business environment in Russia is marred by the fact that organized criminals control much of the Russian economy. The consequences for honest entrepreneurs are manifold. Security expenses drain resources (as a case in point, in the company investigated here, 18 of its 50 employees were security staff). The strength of the Russian mafia has contributed to a blurring in the eyes of ordinary Russians between crime and business, and this has harmed the social image of entrepreneurs. At the same time, there is consensus among experts that due to a deficient tax system, few Russian businesses can avoid involvement in the "shadow" or "gray" economy. According to the Expert Institute in Moscow, up to 75 percent of firms engage in the most common forms of "shadow" activity: concealing a considerable proportion of income, placing capital abroad, and evading excise duty by smuggling.

\section{Czech SME Sector: Foundations so Tiny}

Until 1989, Czechoslovakia had one of the toughest regimes concerning private enterprise among the communist countries. Private businesses were violently nationalized or collectivized in the 1950s. Any entrepreneurial activities were forced into the informal economy. The prompt revival of the SME sector in Czechoslovakia in the first years after the fall of the "iron curtain" is thoroughly analyzed in a study conducted by Benacek (1994). Benacek claims that from the start, the impact of the emerging small legal and informal ventures were largely underestimated by official statistics and substantially contributed to an economically smooth transition.

We can make several straightforward observations: SMEs account for one third of the Czech GDP and for close to two thirds of employment, which has remained more or less stable over the last 10 years. This holds for the accounting value added as well, which stayed close to $53 \%$ throughout the 10 years. On the contrary, three indicators have changed significantly and suggest that the SME sector has come through an intensive consolidation. On one hand, its share of exports and imports has gone up seven and six percentage points respectively, meaning that SMEs are now more involved in international trade. Moreover, the breakthrough appears around the years 2004/2005, when Czech Republic entered the EU. On the other hand, SMEs invest relatively more now as they are rather correcting the underinvestment from the earlier period.

\section{Time Series Model Overview}

A time series is a set of observations obtained by measuring a single variable regularly over a period of time. In a series of inventory data, for example, the observations might represent daily inventory levels for several months. A series showing the market share of a product might consist of weekly market share taken over a few years. A series of total sales figures might consist of one observation per month for many years. What each of these examples has in common is that a variable was observed at regular, known intervals over a certain length of time. Thus, the form of the data for a typical time series is a single sequence or list of observations representing measurements taken at regular intervals.

One of the most important reasons for doing time series analysis is to try to forecast future values of the series. A model of the series that explained the past values may also predict whether and how much the next few values will increase or decrease. The ability to make such predictions successfully is obviously important to any business or scientific field.

The Time Series Modeler procedure estimates exponential smoothing, univariate Autoregressive Integrated Moving Average (ARIMA), and multivariate ARIMA (or transfer function models) models for time series, and produces forecasts. The procedure includes an Expert Modeler that automatically identifies and estimates the best-fitting ARIMA or exponential smoothing model for one or more dependent variable series, thus eliminating the need to identify an appropriate model through trial and error. Alternatively, you can specify a custom ARIMA or exponential smoothing model 


\section{Exponential Smoothing Models}

The following notation is specific to exponential smoothing models where:

- $\alpha$ is the level smoothing weight

- $\Upsilon$ is the trend smoothing weight

- $\varnothing$ is the damped trend smoothing weight

- $\delta$ is the season smoothing weight

The estimation and forecasting of the exponential smoothing is the sum of the squares of the one-step ahead prediction error, $\sum\left(\mathrm{Y}_{\mathrm{t}}-\hat{\mathrm{Y}}_{\mathrm{t}-1}(1)\right)^{2}$ is minimized to optimize the smoothing weights.

Simple exponential smoothing has a single level parameter and can be described by the following equations:

$$
\begin{gathered}
\mathrm{L}(\mathrm{t})=\alpha \mathrm{Y}(\mathrm{t})+(1-\alpha) \mathrm{L}(\mathrm{t}-1) \\
\hat{\mathrm{Y}}_{\mathrm{t}}(\mathrm{k})=\mathrm{L}(\mathrm{t})
\end{gathered}
$$

Holt's exponential smoothing has level and trend parameters and can be described by the following equations:

$$
\begin{gathered}
\mathrm{L}(\mathrm{t})=\alpha \mathrm{Y}(\mathrm{t})+(1-\alpha)(\mathrm{L}(\mathrm{t}-1)+\mathrm{T}(\mathrm{t}-1)) \\
\mathrm{T}(\mathrm{t})=\Upsilon(\mathrm{L}(\mathrm{t})-\mathrm{L}(\mathrm{t}-1))+(1-\Upsilon) \mathrm{T}(\mathrm{t}-1) \\
\hat{\mathrm{Y}}_{\mathrm{t}}(\mathrm{k})=\mathrm{L}(\mathrm{t})+\mathrm{kT}(\mathrm{t})
\end{gathered}
$$

Brown's exponential smoothing (Brown, 1959) has level and trend parameters and can be described by the following equations:

$$
\begin{gathered}
\mathrm{L}(\mathrm{t})=\alpha \mathrm{Y}(\mathrm{t})+(1-\alpha) \mathrm{L}(\mathrm{t}-1) \\
\mathrm{T}(\mathrm{t})=\alpha(\mathrm{L}(\mathrm{t})-\mathrm{L}(\mathrm{t}-1))+(1-\alpha) \mathrm{T}(\mathrm{t}-1) \\
\hat{\mathrm{Y}}_{\mathrm{t}}(\mathrm{k})=\mathrm{L}(\mathrm{t})+\left((\mathrm{k}-1)+\alpha^{-1}\right) \mathrm{T}(\mathrm{t})
\end{gathered}
$$

Damped -Trend exponential smoothing has level and damped trend parameters and can be described by the following equations:

$$
\begin{gathered}
\mathrm{L}(\mathrm{t})=\alpha \mathrm{Y}(\mathrm{t})+(1-\alpha)(\mathrm{L}(\mathrm{t}-1)+\varnothing \mathrm{T}(\mathrm{t}-1)) \\
\mathrm{T}(\mathrm{t})=\Upsilon(\mathrm{L}(\mathrm{t})-\mathrm{L}(\mathrm{t}-1))+(1-\Upsilon) \emptyset \mathrm{T}(\mathrm{t}-1) \\
\hat{\mathrm{Y}}_{\mathrm{t}}(\mathrm{k})=\mathrm{L}(\mathrm{t})+\sum_{\mathrm{i}=1}^{\mathrm{k}} \varnothing^{\mathrm{i}} \mathrm{T}(\mathrm{t})
\end{gathered}
$$

Simple seasonal exponential smoothing has level and season parameter and can be described by the following equations:

$$
\begin{gathered}
\mathrm{L}(\mathrm{t})=\alpha(\mathrm{Y}(\mathrm{t})-\mathrm{S}(\mathrm{t}-\mathrm{s}))+(1-\alpha) \mathrm{L}(\mathrm{t}-1) \\
\mathrm{S}(\mathrm{t})=\delta(\mathrm{Y}(\mathrm{t})-\mathrm{L}(\mathrm{t}))+(1-\delta) \mathrm{S}(\mathrm{t}-\mathrm{s}) \\
\hat{\mathrm{Y}}_{\mathrm{t}}(\mathrm{k})=\mathrm{L}(\mathrm{t})+\mathrm{S}(\mathrm{t}+\mathrm{k}-\mathrm{s})
\end{gathered}
$$

Winters' Additive exponential smoothing has level trend and season parameters and can be described by the following equations:

Figure 1 Approach of Marketing Predictive Analytics Methodology

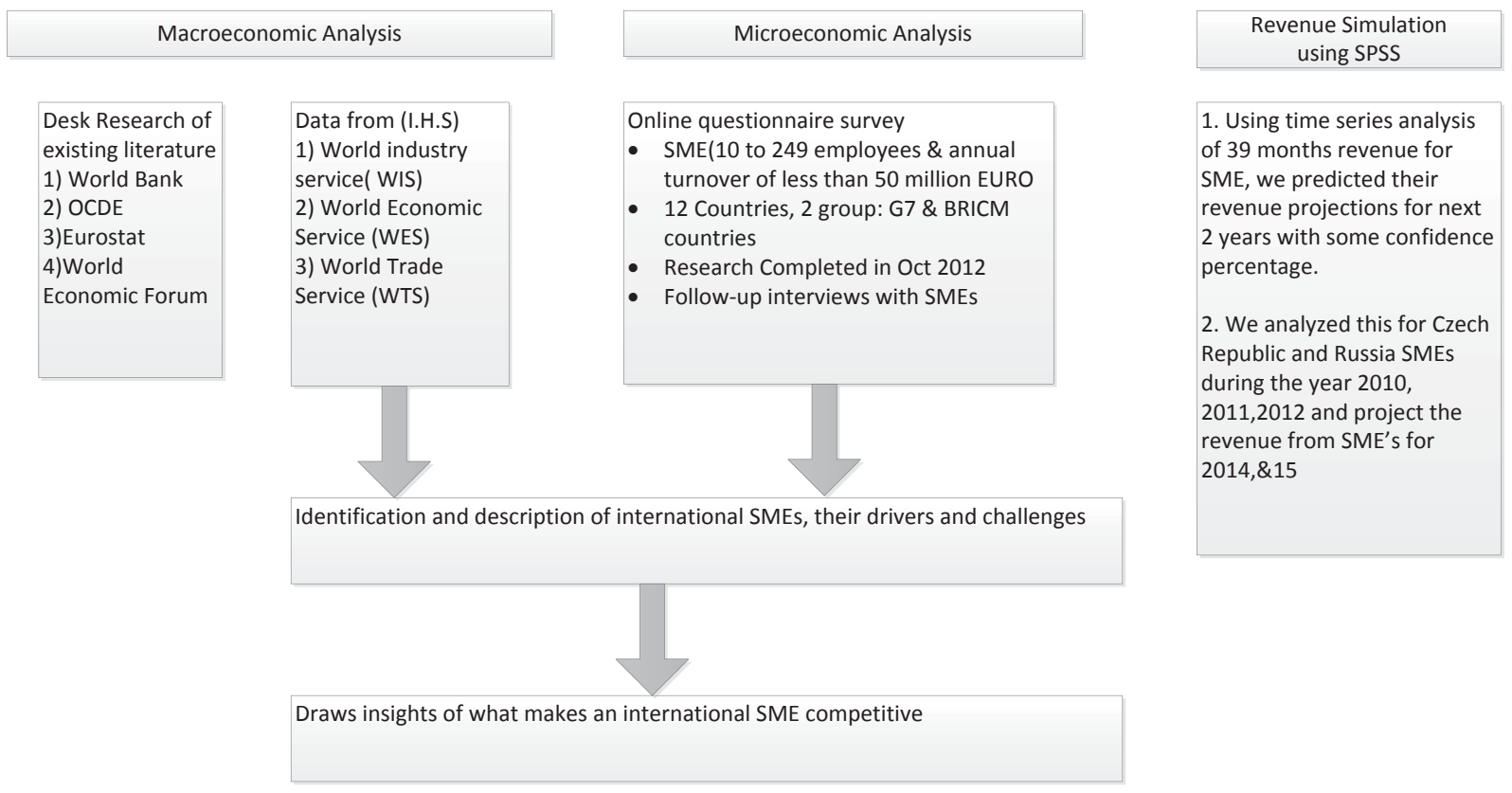

Source: Author \& I.H.S Survey, 2012.

Note: The SME sample for the primary research is based on 410 respondents - owners or members of the senior management team at SMEs having between 10 and 249 employees. The questionnaire is available from the author upon request. 


$$
\begin{gathered}
\mathrm{L}(\mathrm{t})=\alpha(\mathrm{Y}(\mathrm{t})-\mathrm{S}(\mathrm{t}-\mathrm{s}))+(1-\alpha)(\mathrm{L}(\mathrm{t}-1)+\mathrm{T}(\mathrm{t}-1)) \\
\mathrm{T}(\mathrm{t})=\Upsilon(\mathrm{L}(\mathrm{t})-\mathrm{L}(\mathrm{t}-1))+(1-\Upsilon) \mathrm{T}(\mathrm{t}-1)) \\
\mathrm{S}(\mathrm{t})=\delta(\mathrm{Y}(\mathrm{t})-\mathrm{L}(\mathrm{t}))+(1-\delta) \mathrm{S}(\mathrm{t}-\mathrm{s}) \\
\hat{\mathrm{Y}}_{\mathrm{t}}(\mathrm{k})=\mathrm{L}(\mathrm{t})+\mathrm{kT}(\mathrm{t})+\mathrm{S}(\mathrm{t}+\mathrm{k}-\mathrm{s})
\end{gathered}
$$

Winters' multiplicative exponential smoothing has level, trend and season parameters and can be described by the following equations:

$$
\begin{gathered}
\mathrm{L}(\mathrm{t})=\alpha(\mathrm{Y}(\mathrm{t}) / \mathrm{S}(\mathrm{t}-\mathrm{s}))+(1-\alpha)(\mathrm{L}(\mathrm{t}-1)+\mathrm{T}(\mathrm{t}-1)) \\
\mathrm{T}(\mathrm{t})=\mathrm{Y}(\mathrm{L}(\mathrm{t})-\mathrm{L}(\mathrm{t}-1))+(1-\mathrm{Y}) \mathrm{T}(\mathrm{t}-1)) \\
\mathrm{S}(\mathrm{t})=\delta(\mathrm{Y}(\mathrm{t}) / \mathrm{L}(\mathrm{t}))+(1-\delta) \mathrm{S}(\mathrm{t}-\mathrm{s}) \\
\hat{\mathrm{Y}}_{\mathrm{t}}(\mathrm{k})=(\mathrm{L}(\mathrm{t})+\mathrm{kT}(\mathrm{t})) \mathrm{S}(\mathrm{t}+\mathrm{k}-\mathrm{s})
\end{gathered}
$$

\section{Design of Marketing Predictive Analytics Methodology}

The study has drawn upon recent studies of SMEs, from IHS proprietary data and reports, and most significantly from primary research of SMEs through an online survey.

\section{Performance Indicators}

We identified a group of high-performing SMEs based on their average annual growth rate over the last three years.

These were defined as SMEs who have achieved:

- More than a $10 \%$ average annual growth rate over the last three years for $\mathrm{G} 7$ countries (on average, the G7 countries had a $1.58 \%$ growth in GDP);

- More than $20 \%$ average annual growth rate over the last three years for BRICM countries (on average, the BRICM countries had a $5.84 \%$ growth in GDP).

The study also classified SMEs by key competitive advantage, i.e. were they "efficiency" or "innovation" driven. Of course, all SMEs have a mix of both criteria but, through our research, we were able to classify two groups according to their predominant business characteristic:

- Efficiency-driven companies compete on the basis of efficient production processes, quality product improvements and well-organized logistics services;

- Innovation-driven companies compete by providing new or unique products / services creating their own market.

\section{Revenue Analysis Methodology}

We performed several revenue analyses with various statistical methods and based on different customer segmentations (e.g. customer classification according to the industry or loyalty codes) to receive the prediction with the highest possible quality.

In the end, we selected three methods with the best performance across Russia \& Czech Republic:

- Prediction of total revenue,

- Separate predictions of mean revenue per invoice and of number of invoices, for the whole SME sector together.

The fitting of the time series and the predictions were created in SPSS Modeler with Expert Modeler function.

\section{Process}

1) We used customer relationship management (CRM) to gather information about customers for the countries (CZ \& RU) along with their account number.

2) Each customer is uniquely identified and may have many account numbers associated.

3) The revenue per month aggregated by account number for each country for the last 40 months.

We identified the SME customer segment based on the revenue and ran the SME revenue analysis. Also the clustering with SME was based on the following:

a. Sales channel-it is defined as "A channel to market is the method of getting your product into the customer's (the end user's) hand. This can either be through direct sales, or through a reseller."

b. Loyalty Code - it is defined as "Customer loyalty is all about attracting the right customer, getting them to buy, buy often, buy in higher quantities and bring you even more customers."

The following value was predicted using the time series model:

1) Prediction of total revenue,

2) Prediction of mean revenue per invoice and of number of invoices.

The quality of the model could be improved if the total revenue was divided into two individual time series:

\section{Total revenue $=$ number of invoices $*$ mean revenue per invoice}

The number of invoices and the mean revenue per invoice are then analyzed separately. This brings new insight into the revenue analysis, because the series usually behave differently and this knowledge can be integrated into the further decision process (e.g. although the total revenue is constant, the mean revenue is decreasing while the number of invoices is rising). 


\section{Empirical Results \& Analysis}

Our first group of interest is in international SMEs that operate in two or more countries, typically $70 \%$ of the country's respondents.

Figure 2 Graph representation of International SME Operation in 2 or more countries

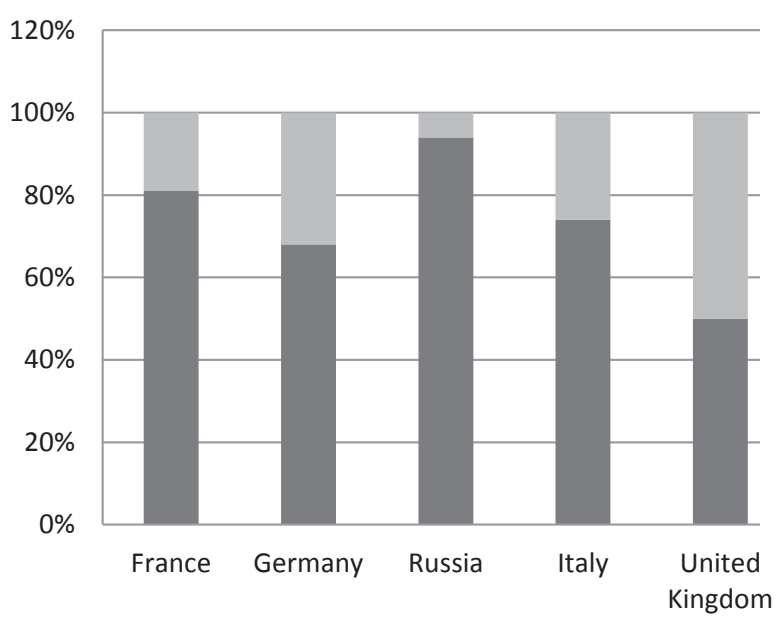

Source: I.H.S Survey, 2012.

Table 1 Percentage of Activities for SMEs in Europe

\begin{tabular}{|l|l|c|c|}
\hline S. No & \multicolumn{1}{|c|}{ Country } & $\begin{array}{c}\text { National } \\
\text { Activities } \\
\text { (in \%) }\end{array}$ & $\begin{array}{c}\text { International } \\
\text { Activities } \\
\text { (in \%) }\end{array}$ \\
\hline 1 & France & $19 \%$ & $81 \%$ \\
\hline 2 & Germany & $32 \%$ & $68 \%$ \\
\hline 3 & Russia & $6 \%$ & $94 \%$ \\
\hline 4 & Italy & $26 \%$ & $74 \%$ \\
\hline 5 & United Kingdom & $50 \%$ & $50 \%$ \\
\hline
\end{tabular}

Source: I.H.S Survey, 2012.

\section{International SMEs Have Developed Multi-Faceted International Activities}

Small and medium-sized enterprises are affected by globalization while being increasingly forced to think and act internationally. The first finding of this study is that SMEs' internationalization no longer has a limited focus on exporting / importing, but has become a much more differentiated business activity encompassing subcontracting as well as technical or commercial cooperation. SMEs may be engaged in cross-border partnerships and foreign investments to capitalize on new opportunities. Smaller SMEs are less internationalized than bigger SMEs, but even for them, internationalization today is a reality. While $80 \%$ of SMEs with 50 to 249 employees are operating at an international level, $66 \%$ of SMEs with 10 to 49 employees are international. One point to notice, nevertheless, is that the size difference is still marked when analyzing the share of small-sized enterprises with more complex forms of internationalization, or a combination of more than one form of internationalization. The modern SME may well be engaged in international business activities beyond IMPORT/EXPORT.

Figure 3 Percentage of SMEs involved in international business activities

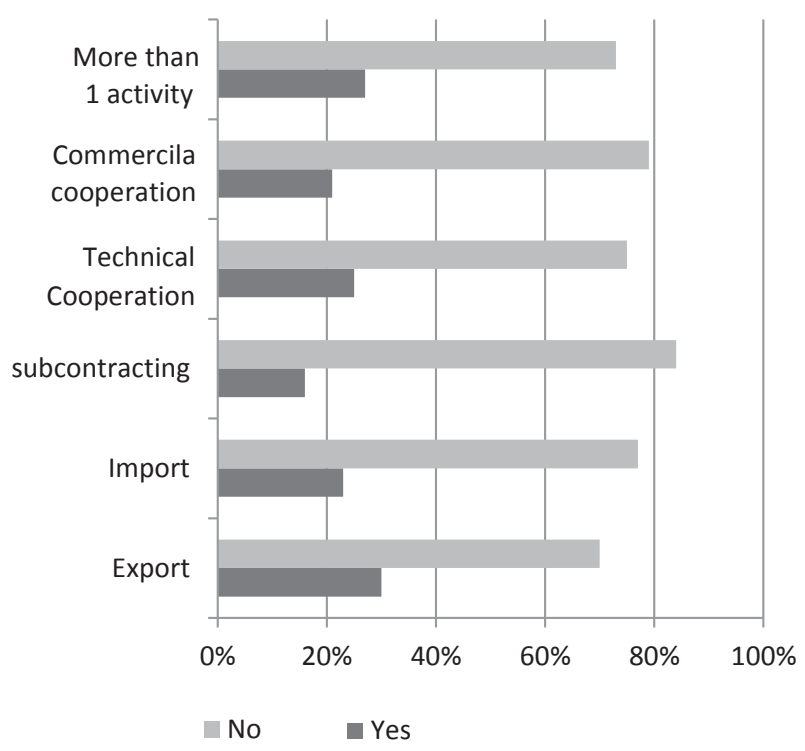

Source: I.H.S Survey, 2012.

Note: Technical cooperation is defined for example, sharing know-how technologies etc. Commercial cooperation is defined as marketing, distribution etc.

Our survey identified a high number of SMEs having international activities within their first five years of existence. For instance, while $27 \%$ of all SMEs have more than one international activity, this indicator rises to $31 \%$ of SMEs with less than five years of trading, despite having had less time to expand their businesses (a general assumption would likely be that the figure would be much lower for younger SMEs). This demonstrates a growing trend towards the internationalization of SMEs.

Young international SMEs are a reality of today's economy and are, in our survey, responsible for an important part of SME internationalization. Recent literature points to a growing number of such firms trading internationally within the first five years of their creation. These 'born global' SMEs see themselves as international rather than national players. 
Interestingly, these 'born global' SMEs are also more prevalent in BRICM countries (24\%) than in G7 countries $(13 \%)$. The rationale behind could be that BRICM-based small and medium-sized enterprises are strategically more focused on international markets than their G7 peers.

\section{Logistics Service}

A World Bank study on logistics performance - "Connecting to Compete" - includes an index built around a survey of logistics professionals who evaluate the logistics environment in the countries where they work, providing information on the quality of infrastructure, the performance of core services, the ease of trade clearance procedures, and the time, cost, and reliability of import and export supply chains.

The table below shows the logistics performance index (score) between Russia and Czech Republic.

The overall Logistics Performance Index score reflects perceptions of a country's logistics based on efficiency of customs clearance process, quality of trade- and transport-related infrastructure, ease of arranging competitively priced shipments, quality of logistics services, ability to track and trace consignments, and frequency with which shipments reach the consignee within the scheduled time. The index ranges from 1 to 5, with a higher score representing better performance. The data is derived from Logistics Performance Index surveys conducted by the World Bank in partnership with academic and international institutions, and private companies/ individuals engaged in international logistics. The 2009 round of surveys covered more than 5,000 country assessments by nearly 1,000 international freight forwarders. Respondents evaluate eight markets on six core dimensions on a scale from 1 (worst) to 5 (best). The markets of the respondent's country are chosen based on three considerations: the most important export and import markets, random selections, and, for landlocked countries, neighboring countries that connect them with international markets. Scores for the six areas are averaged across all respondents and aggregated to a single score using principal components analysis. Details of the survey methodology and index construction methodology are in Arvis et al. (2010).

Figure 4 Logistics Performance Index Logistics performance index: Overall ( $1=$ low to $5=$ high)

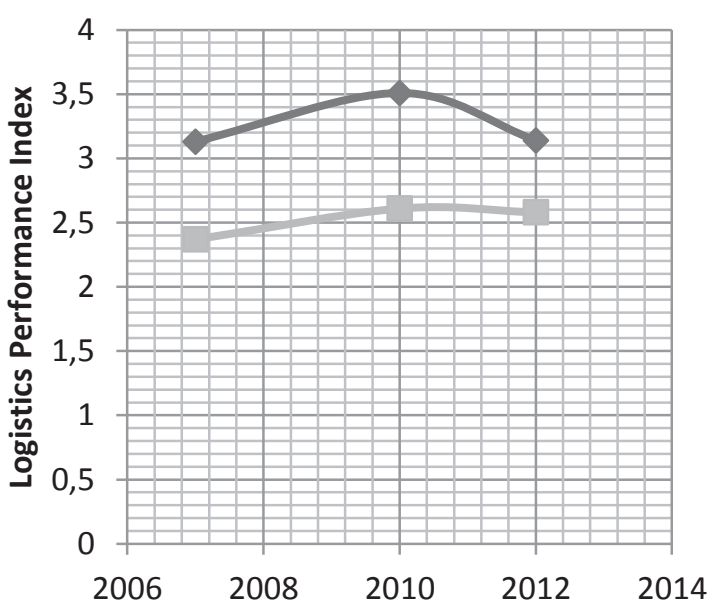

Source: World Bank (2007 to 2012).

For BRICM SMEs logistics are seen as having a strong positive effect on their business performance.

The table below shows the percentage of G7 SMEs and BRICM SMEs that consider logistics as having a "strong positive effect" on their business performance. BRICM SMEs consistently value logistics services higher than their G7 peers, often to a factor of two or more. On average, $14 \%$ of G7 SMEs consider logistics services as fundamental to their strong business performance compared with $27 \%$ of BRICM-based SMEs.

Table 2 What effect do you think logistics can have on the following aspect of your business performance?

\begin{tabular}{|l|c|c|c|}
\hline Business Performance & SMEs & BRICM SMEs & G7 SMEs \\
\hline Increasing Sales & $27 \%$ & $38 \%$ & $19 \%$ \\
\hline Opening new markets & $26 \%$ & $38 \%$ & $17 \%$ \\
\hline Accessing new products, materials or suppliers & $21 \%$ & $31 \%$ & $13 \%$ \\
\hline Differentiating your products or service offering & $20 \%$ & $28 \%$ & $14 \%$ \\
\hline Reducing your need for long term capital & $16 \%$ & $21 \%$ & $13 \%$ \\
\hline Reducing operating cost & $15 \%$ & $19 \%$ & $12 \%$ \\
\hline Reducing stock obsolescence & $14 \%$ & $18 \%$ & $11 \%$ \\
\hline
\end{tabular}

Source: I.H.S survey, 2012. 


\section{International Competitive Advantages - Internationalization as a Driver to Performance}

Internationalization is seen as an opportunity to increase sales, while it additionally affects the firm's competitiveness in other ways too. These include, for instance, through improved cost-efficiency by subcontracting abroad, developing know-how and technology competencies via technical cooperation, and extending product ranges through commercial partnerships. From our survey, we observe two interesting findings:

- For $41 \%$ of SMEs, the main reason to develop international activities is to access new markets;

- For $31 \%$ of our respondents, the main reason to develop international activities is linked to longterm business growth ('Access to know-how and technology' and 'Diversification of product / service portfolio').

Table 3 Question: What are your main reasons to increase your international business activity?

\begin{tabular}{|l|c|}
\hline $\begin{array}{l}\text { Reason to increase international } \\
\text { activities }\end{array}$ & $\begin{array}{c}\text { International } \\
\text { SME's }\end{array}$ \\
\hline Access to new markets & $41 \%$ \\
\hline Access to know-how and technology & $17 \%$ \\
\hline Diversification of product/service portfolio & $14 \%$ \\
\hline Additional production capacity & $11 \%$ \\
\hline High labor cost in the domestic market & $7 \%$ \\
\hline Access to cheaper raw material & $4 \%$ \\
\hline Access to capital & $3 \%$ \\
\hline Access to labor force & $2 \%$ \\
\hline More flexible regulation & $1 \%$ \\
\hline
\end{tabular}

Source: I.H.S. survey 2012.

Encouraged by initiatives from the World Trade Organization (WTO) and the General Agreement on Tariffs and Trade (GATT), as well as regional agreements such as MERCOSUR and the EU Single Market, subcontracting, technical and commercial cooperation can strengthen the ability of SMEs to compete successfully on the international level while continuing to maximize their local strengths. One example of can be found in the northern Mexican regions. Small and medium-sized enterprises there have developed a specific form of cross border partnership that takes advantage of the innovative US business environment, allowing access to know-how and technology.

\section{Revenue Analysis Result}

The following table summarizes the total revenue prediction using SPSS based on the approach described above:

Table 4 SPSS Revenue Analysis for Czech Republic and Russia

\begin{tabular}{|c|c|c|c|c|}
\hline S. No & Country & Year & $\begin{array}{c}\text { Revenue Increase } \\
\text { From } 2012 \text { in \% }\end{array}$ & R2 \\
\hline \multirow[t]{3}{*}{1} & \multirow{3}{*}{$\begin{array}{l}\text { Czech } \\
\text { Republic }\end{array}$} & 2013 & $1.9 \%$ & \multirow[t]{3}{*}{0.671} \\
\hline & & 2014 & $4.9 \%$ & \\
\hline & & 2015 & $8.0 \%$ & \\
\hline \multirow[t]{3}{*}{2} & \multirow[t]{3}{*}{ Russia } & 2013 & $16.2 \%$ & \multirow[t]{3}{*}{0.899} \\
\hline & & 2014 & $33.0 \%$ & \\
\hline & & 2015 & $49.9 \%$ & \\
\hline
\end{tabular}

Source: Author.

The following graph (figure 5) shows the prediction of mean revenue per invoice for Czech Republic for 2013 - 2015. Since the behavior of the mean revenue per invoice in 2010 differs from the rest of the period, we discarded the first 12 observations from the analysis. We can clearly see that the seasonal behavior continues for year 2013-2015.

The following graph (figure 6) shows the prediction of the number of invoices for Czech Republic which shows that the number of invoices increases steadily which proves that there is a steady increase in the number of shipments year on year based on past historical data of

Figure 5 Prediction of mean revenue per invoice for Czech Republic

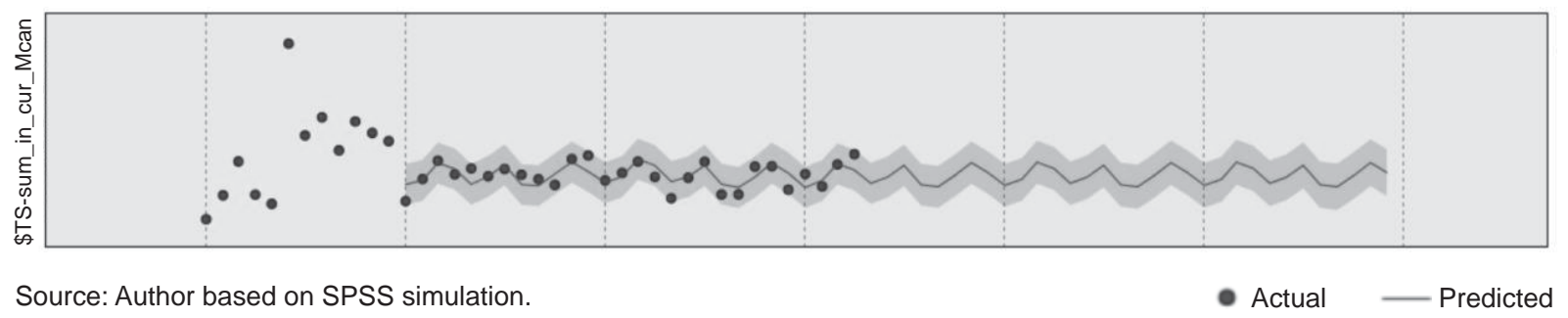


Figure 6 Prediction of Total Number of Invoices for Czech Republic

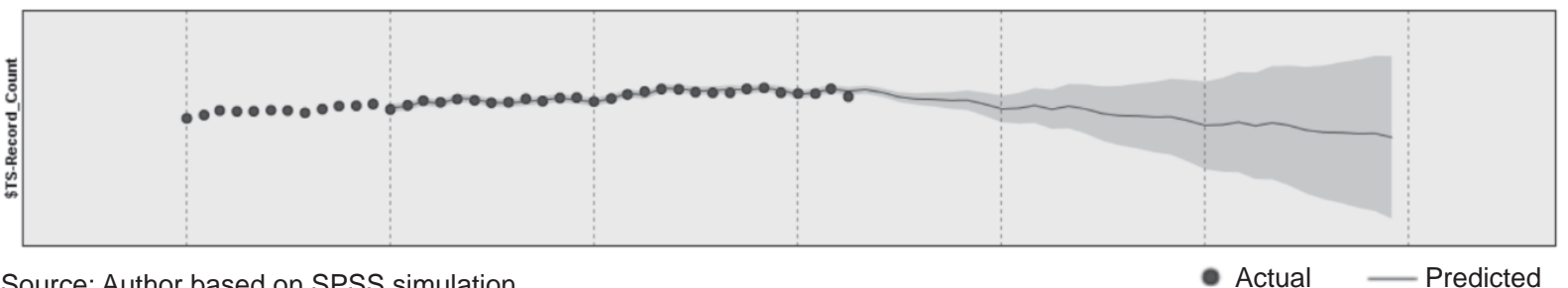

Source: Author based on SPSS simulation.

Predicted

Figure 7 Prediction of Total Revenue for Czech Republic

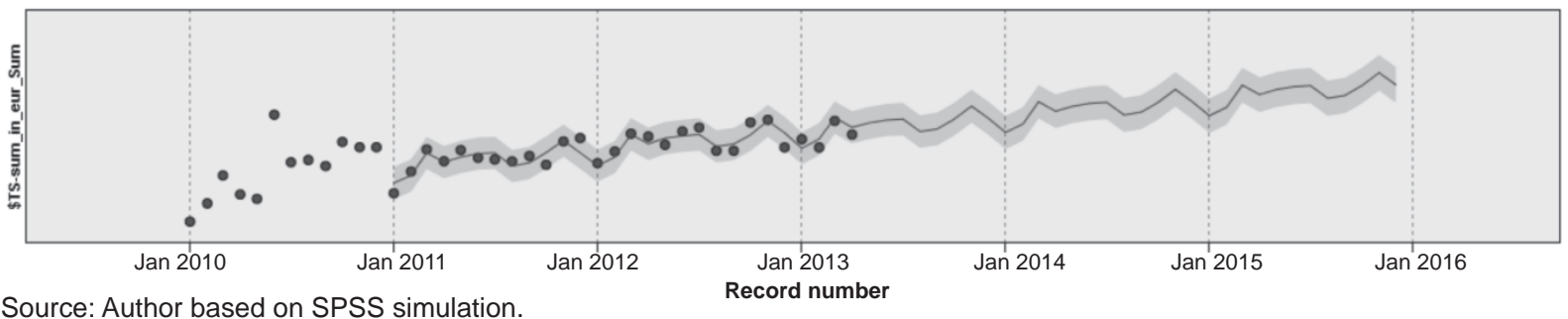

Source: Author based on SPSS simulation.

Figure 8 Mean Revenue per invoice for Russia

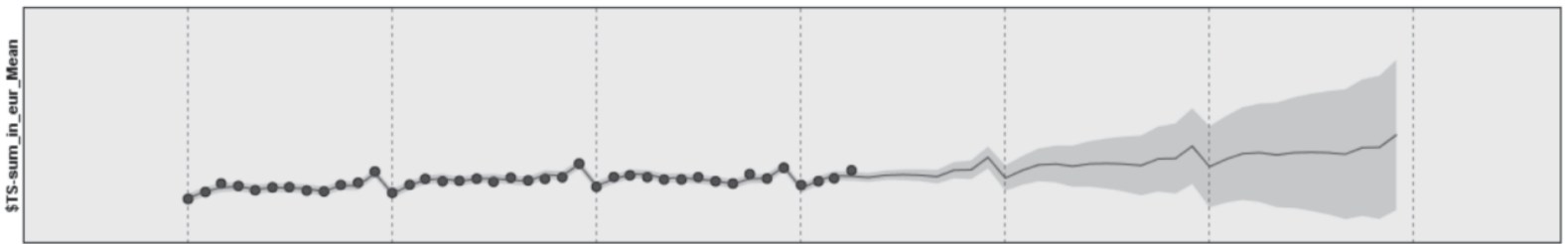

Source: Author based on SPSS simulation.

Figure 9: Total number of invoices for Russia

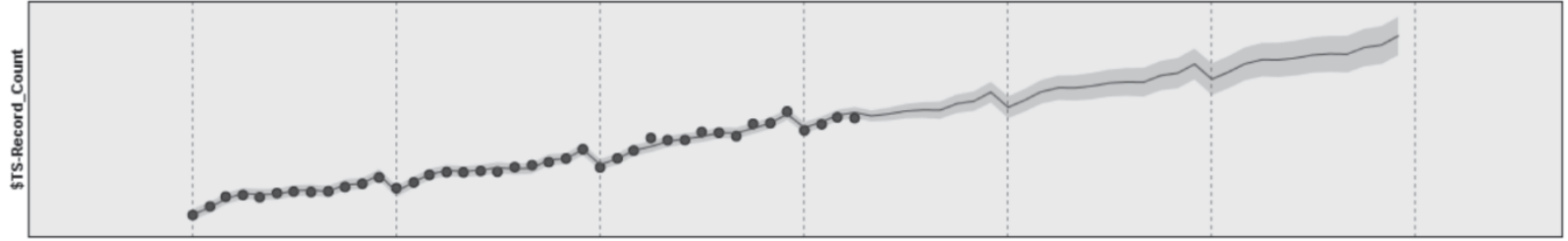

Source: Author based on SPSS simulation.

shipments. Nevertheless, beyond 2015, it looks like the number of invoices will decline; however, this may not be valid as we do not have any historical data beyond 2010 to predict the future values accurately.

The following graph (figure 7) shows the prediction of total revenue for Czech Republic. We can clearly see that historical data for the year 2010 does not show any patterns. Hence it was rejected. However for the years 2011, 2012 we can see patterns in historical data from which we can see that there is an increase in revenue by $1.9 \%$ in $2013,4.9 \%$ in $2014 \& 8 \%$ by 2015 .
The following graph (figure 8) shows the prediction of mean revenue per invoice for Russia. It shows there is an increasing seasonal trend in the mean number of invoices based on 36 months historical analysis. This shows that the seasonality continues for the following years 2013 till 2015.

The following graph (figure 9) shows that the prediction of the number of invoices for Russia increases for the year 2013-2015 and follows seasonal behavior patterns. The following graph (figure 10) shows the prediction of total revenue for Russia based on historical data from 


\section{Figure 10 Prediction of Total Revenue for Russia}

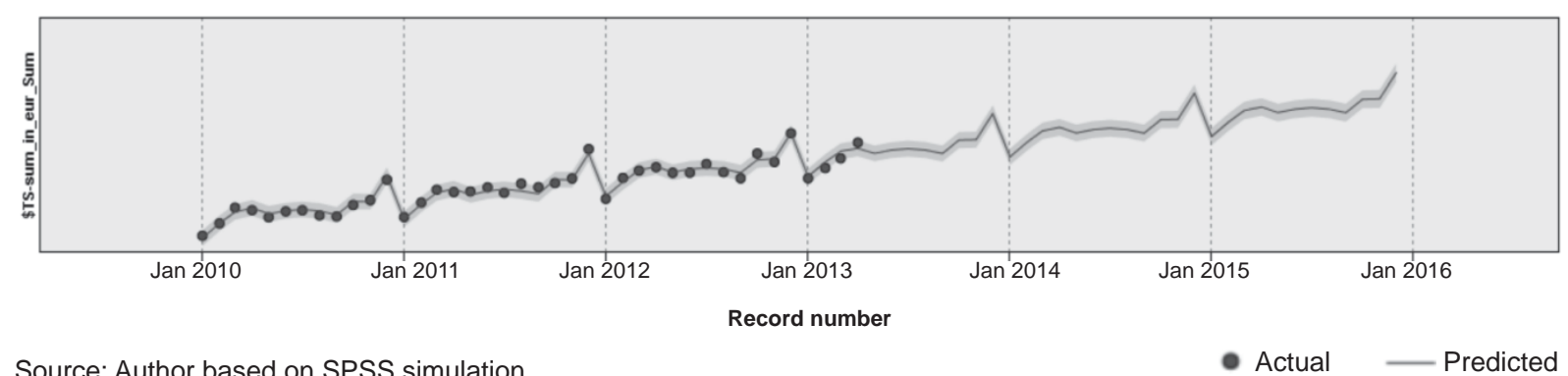

Source: Author based on SPSS simulation

- Actual — Predicted

2010 to 2012. We can see that unlike Czech Republic, the data follow patterns. It shows clearly that Russian revenue will increase by $16.2 \%$ in $2013,33 \%$ in 2014 \& $49 \%$ in 2015 .

\section{Conclusion}

So, do SMEs that trade internationally perform better? Our research strongly suggests that they do.

We were surprised by the high proportion of our sample that traded internationally. Given this sample's profile it is reasonable to expect that international SMEs figure significantly in our high-performers category and they do outperform their domestic-only peers. So the idea of internationalization being a driver of business performance is certainly supported by our results. The reasons for this could be that international SMEs transfer best practices developed internationally to their overall business, as well as the idea that SMEs which expand internationally are more likely to be ambitious.

Evidently, SMEs are increasingly integrated into the global economy and not limited to regional / national activities, but in fact have gone beyond what is often the first step of internationalization: exporting / importing. Among the SMEs surveyed, $73 \%$ of the companies had at least one international activity and, among them, $43 \%$ were involved in exporting activities - SMEs are not just local service providers.

There are further points of interest with regard to international SMEs which support our conclusion include. For example, international SMEs perform better than the average domestic SME; $26 \%$ of the international SMEs in the sample were high performers, while only $13 \%$ of the domestic-only SMEs were measured in that study. In fact, more than $30 \%$ of our respondents see the increase of their international activities as a way to improve their long-term business growth through acquisition of knowhow and product diversification.
SMEs are increasingly focused on doing business internationally with younger companies which are more likely to be engaged in overseas markets despite having had less time to grow their businesses. Often referred to as 'born global', these young international SMEs are a reality of today's economy often exploiting the spread of inexpensive communication technologies and efficient logistics services.

SMEs in BRICM countries are more likely to have international activities than SMEs in G7 countries: one explanation for this is that a real business driver is to set up strong business relationships with high consumption per capita developed markets. In fact, $70 \%$ of BRICM high-performing SMEs have the majority of their international clients, partners and subcontractors in developed countries. This also suggests they are better placed to respond to opportunities in new geographical markets than many G7 SMEs in the future.

High-performing international SMEs cited three key challenges to their export efforts: 'lack of knowledge of foreign markets', 'high customs duties in the destination country' and 'establishing contacts with foreign partners / customer base.' Governments looking to boost the competitiveness of their SMEs should give serious consideration to these factors.

Logistics is seen as having a positive effect on many aspects of a SME's performance with a distinct difference between G7 countries (where logistics is seen as a way to reduce operating costs) and BRICM countries (where logistics is seen as a means to differentiate their product or service offering).

Finally, and impacting all SMEs, there is a real lack of reliable and up-to-date information about SMEs on a country by country basis, despite the significant contribution made by SMEs to employment (typically 35-45\% of total employment) and value added to an economy (typically $30-40 \%$ of total value added). This lack of information is itself a restraint upon SMEs since it 
restricts their ability to organize while presenting a case around credible data and information, basically to have a "voice." Linking back to the internationalization thread of this report, as one respondent explained, banks, investors, and institutions do not think of SMEs as operating at an international level. This is certainly in part due to the lack of reliable information on this subject which hinders the construction of a clear vision for such a heterogeneous group. Evidently, there is a clear opportunity for policy makers to support this sector as a means to create more jobs, add value, and increase export earnings.

From the SPSS analysis, we can see that there is immense potential in the SME sector, especially in Czech Republic. If we can provide a portfolio of products designed for SMEs, we can activate this potential and increase the revenue of growth for the next couple of years through predictions based on analysis of the past few years' performances.

\section{References}

Brown, R., 1959. Statistical Forecasting for Inventory Control. McGraw-Hill, New York. Bunn, D.W., Farmer, E.D., 1985. Economical and operational

Arvis, J. F., Mustra, M. A., Ojala, L., Shepherd, B., Saslavsky, D. (2010). Connecting to Compete 2010: Trade Logistics in the Global Economy World Bank. Washington, DC.

Benacek, V. (1994). The Rise and the Obstacles to Authentic Entrepreneurship during Transition: The Case of the Czech Private Businesses. Working Papers of CERGE-EI no. $53,1994$.

Chen, H. L., Huang, Y. (2004). The establishment of global marketing strategic alliances by small and medium enterprises. Small Business Economics, 22(5): 365-377.

Kalantaridis, C. (2004). Internationalization, strategic behavior, and the small firm: a comparative investigation. Journal of Small Business Management, 42(3): 245-262.
Karagozoglu, N., Lindell, M. (1998). Internationalization of small and medium-sized technology-based firms: An exploratory study. Journal of Small Business Management, 36, 44-59.

Malekzadeh, A. R., Nahavandi, A. (1985). Small business exporting: Misconceptions are abundant. American Journal of Small Business, 9: 7-14.

Schneider, F. (2003). The Size and Development of the Shadow Economies and Shadow Economy Labor Force of 22 Transition and 21 OECD Countries: What Do We Really Know? The Informal Economy in the EU Access Countries: Size, Scope, Trends and Challenges to the Process of EU Enlargement, Center for Study of Democracy, 23-61.

Shridhar, M. (2006). Incubators and science parks: strategies for developing countries, (accessed July 2, 2007), [available at: www.anprotec.org.br/idisc/pdfs/ publiacoes/155.doc].

Tesar, G., Moini, A. H. (1998). Longitudinal study of exporters and nonexporters: A focus on smaller manufacturing enterprises. International Business Review, 7(3): 291-313.

Underwood, T. (2004) Export Assistance for Small and Medium Sized Enterprises Offered by the International Trade Administration, Washington, DC: US Department of Commerce.

Author

Pramod Dasan, MBA

Faculty of International Relations

University of Economic

Prague Czech Republic pramod.dasan@gmail.com

This article has been created with financial support of the Internal Grant Agency of the University of Economics, Prague, No. of project mF/13/2012. 